\title{
A COMPARATIVE MICROSCOPIC STUDY OF THE INTERCALATED DISCS OF VERTEBRATE HEART MUSCLE
}

\author{
H. E. JORDAN AND K. B. STEELE
}

From the Anatomical Laboratory of the University of Virginia

TWENTY-THREE FIGURES

CONTENTS

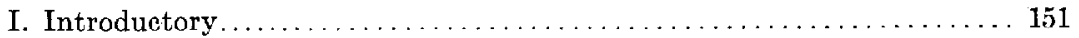

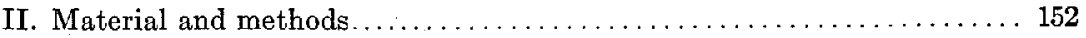

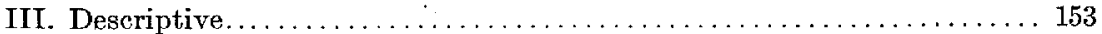

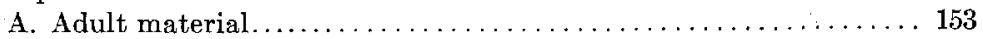

1. Monkey................................ 153

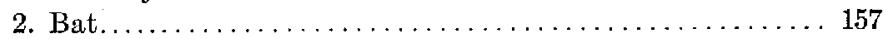

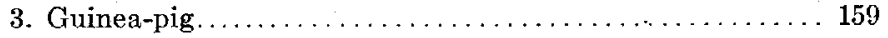

4. Chipmunk ............................... 160

5. Opossum................................ 162

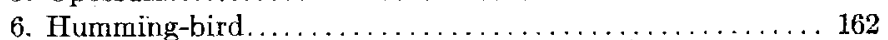

7. Turtle.............................. 162

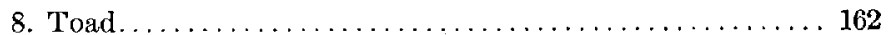

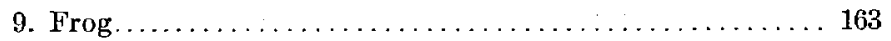

10. Trout................................ 164

B. Young and foetal material. . . . . . . . . . . . . . . . . . 165

1. Guinea-pig............................. 165

a. Second, third and fourth weeks........... 165

b. First week ........................... 165

c. Last week of gestation.................... 165

2. Cat of four days............................ 165

3. Child of four years........................... 165

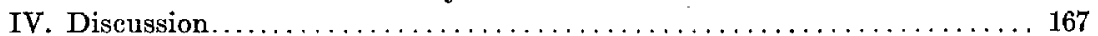

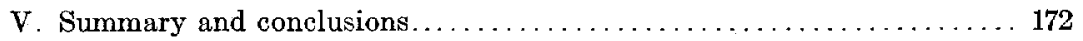

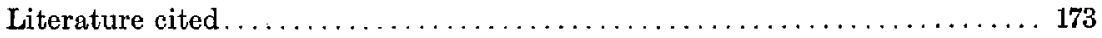

\section{INTRODUCTORY}

On the basis of histologic findings in the heart of the hummingbird, Jordan ('11) believes he has demonstrated that intercalated discs are not correctly interpreted as intercellular elements marking cell boundaries, as recently again urged in the papers by 
Zimmermann ('10) and his students, Palczewska ('10) and Werner ('10). It is the purpose, in part, of this investigation to present further facts in support of the non-cellular interpretation of vertebrate heart muscle.

Marceau ('04) states that he was unable to demonstrate discs in the heart muscle of vertebrates lower than birds; $;^{1}$ also in goose and duck. Moreover, he says that discs develop only some time after birth. The further object of our research is to test the factual basis of these assertions and to determine, if possible, from structural marks, the probable function of the intercalated dises.

\section{MATERIAL AND METHODS}

The material studied includes heart muscle of adult human, monkey, sheep, bat, cat, guinea-pig, mouse, rabbit, chipmunk, opossum, humming-bird, lizard, turtle, toad, frog and trout; also of guinea-pig of last week of gestation, and of first, second, third and fourth wecks of post-natal life; of a cat embryo of four days, and of a four-year-old child; and of Limulus. ${ }^{2}$

Zimmermann's technic ${ }^{3}$ was employed except for adult human, cat, rabbit, sheep and lizard hearts. Mammalian cardiac muscle of the latter group has been fully described and illustrated by Werner. We shall confine our descriptions for the most part to the heart muscle of forms not previously studied. The descriptions in every instance apply to the ventricular tissue.

'In the second volume (1911) of 'Plasma und Zelle,' Heidenhain says 'Schaltstücke wurden bisher in keinen Falle bei niederen Wirbeltiere beobachtet; sie finden sich by Vögeln zum ersten Male.'

${ }^{2}$ We are indebted to Messrs. H. F. Jackson and F. L. Powers for kindly collecting the material of toad, frog, trout and Limulus at Cold Spring Harbor, I. I.; and to Dr. W. H. Schultz, of the Hygienic Isaboratory, Washington, for the young and foetal guinea-pig hearts.

${ }^{3}$ Following this technic, small pieces of tissue were treated for twenty-four hours with a solution of 90 parts of absolute alcohol plus 10 parts of 25 per cent $\mathrm{HNO}_{3}$. The tissue was then washed in several changes of 94 per cent alcohol or until the Latter remained neutral to litmus paper. It was then passed into distilled water, from which it was transferred to a solution of 1 gram of Grübler's haemalum in $10 \mathrm{cc}$. of water. Here it remained for from eight to ten days when it was washed in distilled water and then carried through the ordinary steps of the paraffin technic. In our own experience we have obtained equally successful preparations by staining sections for twenty-four hours on the slide. 


\section{DESCRIPTIVE}

\section{A. ADULT MATERIAL}

In every case the myocardium consists of a close-meshed network of coarser and finer branching striped muscle trabeculae.

\section{Monkey}

When a large expanse of tissue is under view, the discs are seen to lie more or less closely aggregated in definite regions. There is evidently roughly an alternation of disc-containing and disc-free areas (figs. 1 and 2). On close examination the disccontaining areas for the most part correspond to the axial regions of the mesh. In physical terms these regions correspond to areas of greatest stress during contraction (figs. 1 and 2). The discs appear commonly in three distinct forms: (1) they may be compact and wide, ${ }^{4}$ i.e, as wide as a single fiber; (2) they may be narrow, i.e., not much wider than a single fibril; (3) they may consist of rows of spherical granules, connected severally by a delicate deep-staining membrane. These three main types of discs are all represented in fig. 1. The 'compact' discs under higher magnification are seen to be composed of rows of longer or shorter rod-like granules. The rows of spherical granules usually span the intervals between adjacent dises of more compact forms (forms 1 and 2). The myofibrillae are clearly evident, singly and in bundles, giving the fiber a distinct longitudinal striation. The striations (fibrillae) passing through the smaller dises of form 2 are much coarser than the adjacent fibrils (fig. 1). These fibrils are evidently modified, being probably in a state of greater contraction; and the narrower discs would seem to be foci of still greater contraction in the fibrils. If this interpretation is valid-as many facts about to be detailed very strongly indicate - then the wider discs are reasonably conceived as the result of a fusion or association of narrower discs; and the

" 'Wide' and 'narrow' refer to the transverse axis of longitudinal sections, 'coarse' or 'robust' and 'delicate' to the Iongitudinal axis, and 'deep' and 'superficial' to the diameter of the uncut fiber. 

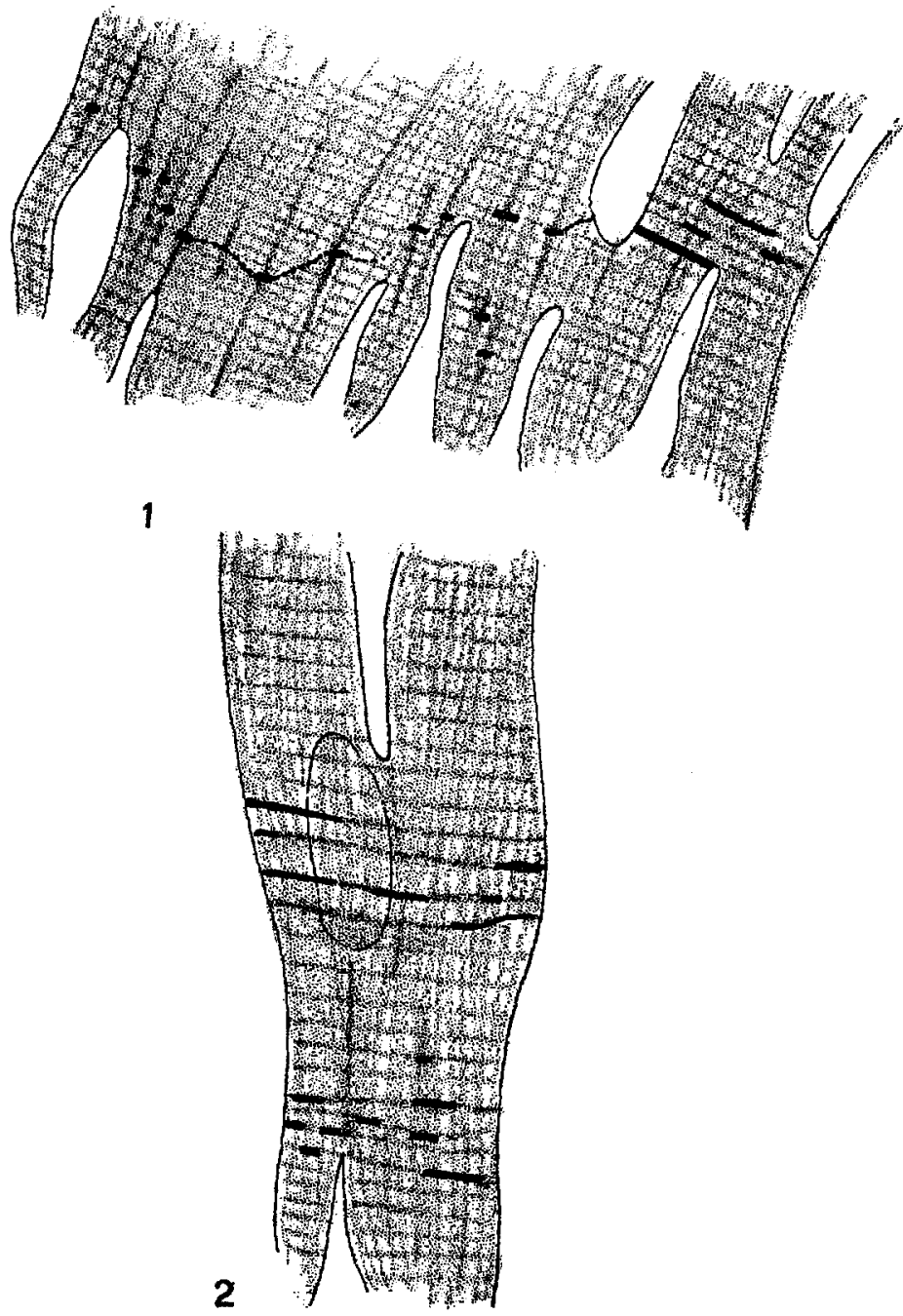

All figures unless otherwise specified are magnified 1800 diameters.

Fig. 1 Expanse of cardiac muscle of monkey in longitudinal section, showing several types of intercalated discs, their general disposition in the axis of the mesh; and their relation to each other, the dark bands, and the myofibrillae.

Fig. 2 Longitudinal section of two medially fused muscle trabecular of monkey heart, showing the axial disposition of the dises, and the super-nuclear location of several. 
rows of granules as areas of local contraction in otherwise relaxed and distinct fibrils, the inter-granular membrane possibly representing a condensed membrane of Heidenhain ( $M$ line; mesophragma, Heidenhain).

The dises are almost invariably at the level of, and, where present, displace the dark (anisotropic) bands. ${ }^{5}$ However, they are frequently wider than these bands. Occasionally, when robust, they may extend approximately halfway or even entirely, through the lighter band (fig. 6). But they are certainly not generally bounded on both 'sides by Krause's membrane (telophragma, Heidenhain), an observation urged in favor of an intercellular interpretation, as has been stated by some investigators, e.g., Heidenhain.

In fig. 2 all of the dises appear as wider or narrower more or less compact granular bands. The two separate collections are localized at the points of stress. One disc appears to span the line of junction. Several lie partially over the nucleus. All are superficial and of comparatively little depth. ${ }^{6}$ These structural variations, superficial and occasional super-nuclear position, render untenable interpretation as cement lincs. Fig. 3 illustrates four successive superficial dises unconnected by 'risers' to form 'steps.' Moreover, they gradually shade laterally into the anisotropic bands which they in part displace. In fig. 4, three dises are shown overlying the deeper nucleus. In fig. 5 are illustrated two wide dises of finely granular character. Such dises are fairly common. In this particular fiber the two dises lie at slightly different depths. The important point is that in passing from a

- The term anisotropic is not here employed in a definitely physical sense. It is used simply to denote the darker-staining substance in the $Q$ and $Z$ band of striped muscle, in accordance with common custom. Careful study of cardiac muscle with the micropolariscope, under the same physical conditions that very strikingly revealed anisotropic vegotable fibers and inorganic crystals, failed, however, to disclose any definitely anisotropic substance in the myofibrillae. The point urged is the similarity between the darker transverse and the intercalated discs. It would seem, moreover, that not all striped muscle ean be resolved into sharply defined isotropic and anisotropic dises. On the other hand, as far as the micropolariscope gives evidence, 'stripes' appear in the absence of anisotropic granules.

'Hence 'discs' strictly defined is a misnomer; they are more properly designated 'bands.' The $Q$ and $J$ 'bands,' moreover, are more correctly denominated 'disces.' 
higher to a lower level of focus, when one disc fades out of view as the other passes in, no differentiated connecting substance ('riser') appears, as one would expect if these two dises represented portions of an irregular cement line cut tangentially, as interpreted by Zimmermann and his students.

The most plausible interpretation, it would seem, must regard the dark-staining granules or rodlets of the 'dises' as local modifications or contractions at anisotropic levels of the myofibrillae.
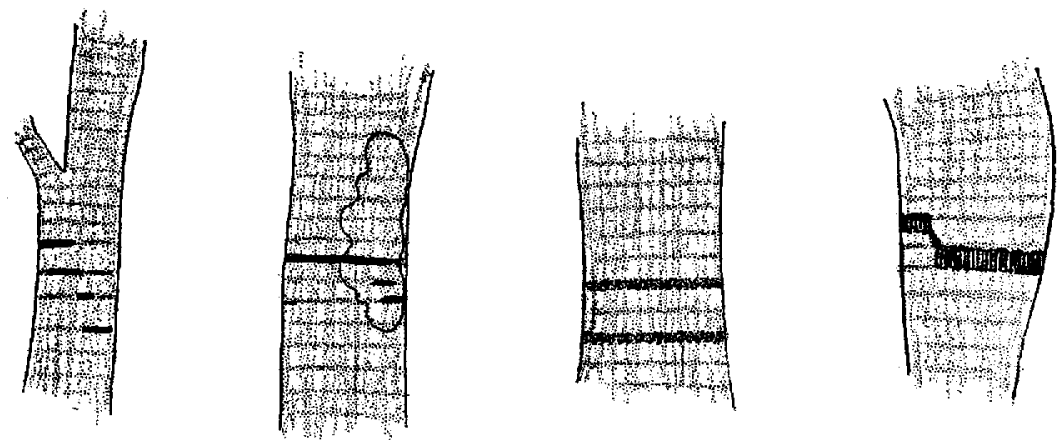

3

4

5

6

Fig. 3 Branching fiber of monkey heart with four plate-like dises, showing their relation to the dark bands.

Fig. 4 Short portion of fiber of monkey heart showing super-nuclear position of three dises.

Fig. 5 Two granular dises of monkey heart at different levels of focus. In passing from the higher to the lower level of focus no connecting membrane or 'riser' appears.

Fig. 6 A two-step, comb-like, disc of monkey heart, in longitudinal width equal to that of the isotropic and two anisotropic dises. The two portions are connected by a coarse deep-staining membrane. The 'teeth' of the 'comb' are interpreted as locally contracted portions of adjacent fibrillae.

Fig. 6 shows a rare variation. Here the disc may extend the longitudinal distance of half or even an entire lighter band. In form it has a 'comb' structure. When at different levels, as here, the several sections are connected by a robust deeply-staining membrane. The appcarance simulates protoplasmic processes or 'intercellular bridges.' However, if this were a correct interpretation, they would undoubtedly be very much more numerous. 
The 'teeth' of the 'comb,' we believe, must be interpreted as local, elongate contractions of the myofibrillae. Occasionally such dises consist of only one or several 'teeth;' again three or four 'combs' may appear in longitudinal series, giving the appearance of a contracted striped insect muscle. Frequently successive dises limit a region of darker sarcoplasm; frequently also dises lie in regions of darker sarcoplasm. The significance of these observations is that they indicate a relationship between dises and a condition of contraction. Possibly the dises outline limits of special physiological states. The loose granular dises are perhaps simply 'comb'-dises with shorter 'teeth.'

\section{2. $B a t$}

In the heart of the bat, in addition to the types of dises described for monkey, there appear dises in the form of a line of dark-staining, connected, spherical granules extending across as many as eight separate fibers; and directly over underlying nuclei (fig. 7). Such a structure does not even vaguely suggest a cell membrane or cement line. It becomes intelligible only in terms of local modifications (contractions?) at approximately the same level in many adjacent fibers. It would seem to represent the morphologic picture of a physiologic state sharply localized longitudinally, widespread laterally. In fig. 8 are shown two series of narrow dises connected by more or less delicate granular inter-dise membranes ('risers'). These inter-connections, and the localization of the dises in the axial region of the muscular mesh, here again suggest the effect, or phase, of a definite physiologic state. The inter-disc membrane may represent less extreme local contractions in the intervening fibrillae, or a dislocated modified membrane of Heidenhain, or possibly simply 'anisotropic' granules obliquely aligned. Careful focussing reveals the fact that these complex step-like dises lie superficially throughout and encircle the fiber in ring-fashion. This single observation disposes definitely of a cell-border interpretation. 

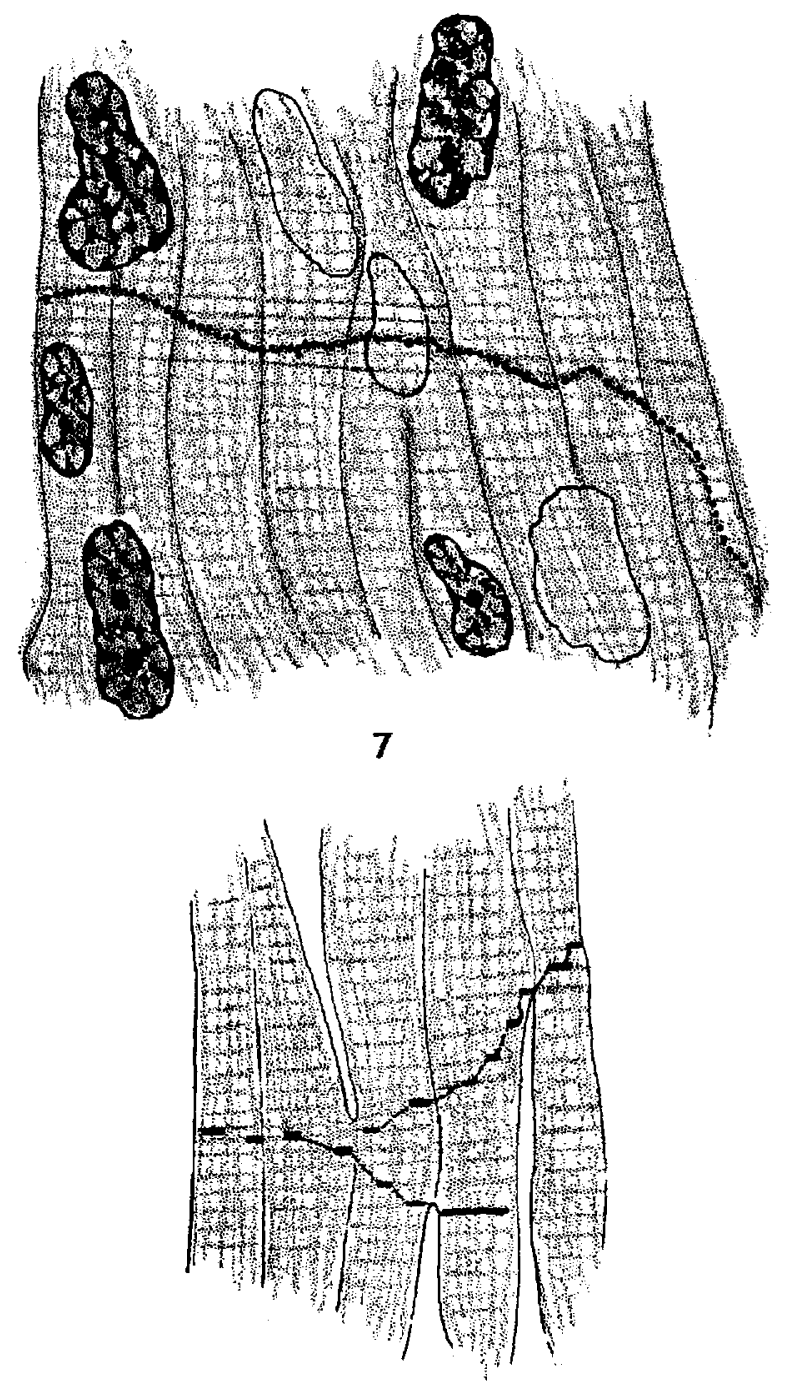

8

Fig. 7 Longitudinal section of cardiac musele of bat, showing a granular intercalated 'disc' running across eight fibers.

Fig. 8 Heart muscle of bat showing two long step-like dises winding superficially around their fibers. The 'riscrs' probably represent anisotropic granules aligned longitudinally, or perhaps a distorted membrane of Heidenhain. 


\section{Guinea-pig}

Fig. 9 illustrates the typical condition in adult guinea-pig. The discs are again aggregated in more or less definite areas; they may be wide or narrow, delicate or robust, compact or loosely granular. At the left, two dises are shown connected by a row of granules; a similar disc, of mono-serial coarse granules, extends uninterruptedly across the two middle fibers. The same condition, producing the disc-structure, prevails at approxi-

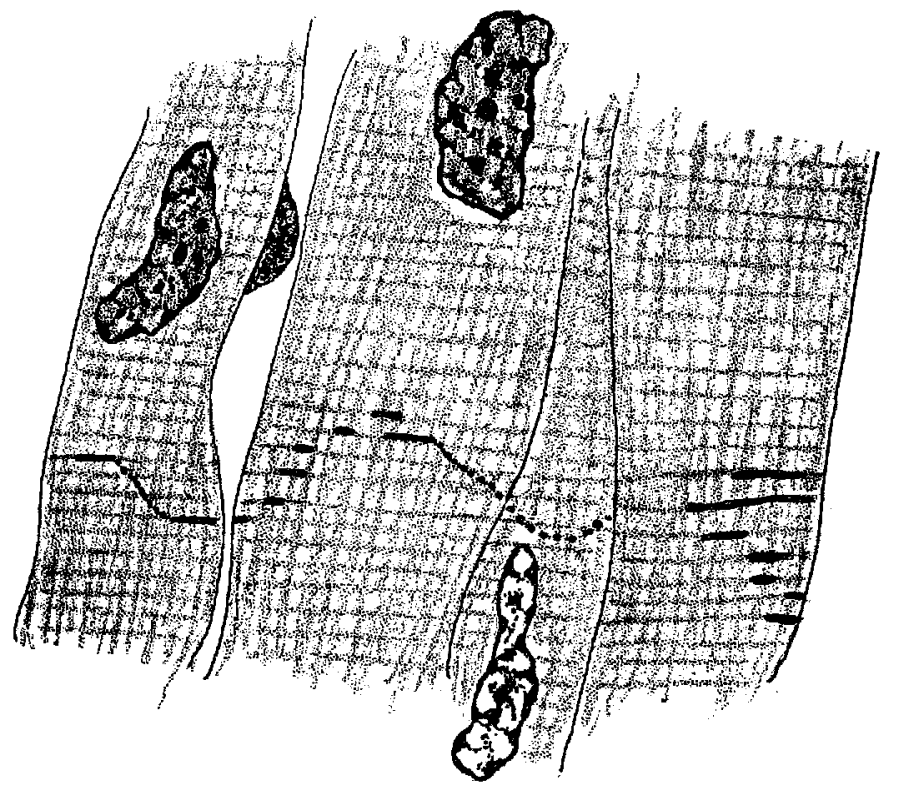

Fig. 9 Section of guinea-pig heart muscle illustrating the several types of discs, and their relation to each other, the fibrillae and the darker bands.

mately the same level in the four adjacent fibers; the appearance is incompatible with a cement line. Fig. 10 shows a disc of three 'steps' and two 'risers' extending across a nucleus. Fig. 11 illustrates a patch of compact and pale granular dises. Fig. 12 shows a variation occasionally met with in the guinea-pig and other mammals. Such a dise has not the remotest resemblance to a cement line or to an intercellular bridge. The thickenings 
(blocks) of the discs are most likely local contractions in the fibrils, the connecting deeply-staining 'membrane' being formed of the lateral coalescence of less extreme locally contracted portions of intervening fibrils; or it represents perhaps a thickened, distorted membrane of Heidenhain; or it may be the product of the combination of both of these elements. This is a more common type of disc in young hearts.

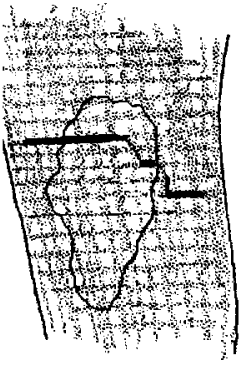

10

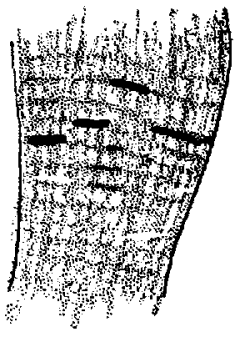

11

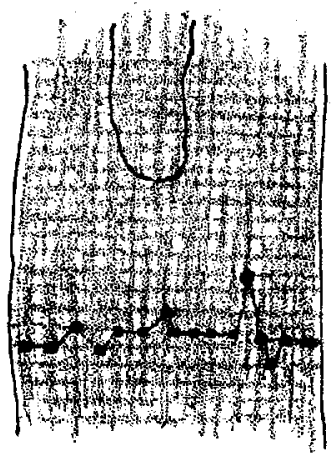

12

Fig. 10 Guinea-pig heart muscle fiber, showing the super-nuclear position of a three-step disc.

Fig. 11 Guinea-pig heart-muscle fiber, showing compact and granular varieties of plate-like dises. The loosely granular dises are the less highly developed type.

Fig. 12 Guinea-pig eardiac fiber, with block-like dises at different anisotropic levels and connected by delicate granular membranes giving a zig-zag appearance to the complete structure. The 'blocks' are locally contracted portions of the fibrillae, the connecting membranes represent probably 'anisotropic' granules in linear arrangement, or one of the 'membranes', i. e., $M$ or $Z$.

\section{Chipmunk}

Heart muscle of the chipmunk exhibits all the types of dises above described. It shows also especially clearly and abundantly a type illustrated in fig. 13. Here the dises appear as oval thickenings on the fibrils. In other locations three or four (still more elongated) may appear at successive anisotropic levels, giving the appearance of deeply-stained striped insect muscle. Fig. 14 
shows a step-like dise with six 'steps' and five 'risers.' The 'steps' consist of deep-staining granules; the 'risers' are more delicate granular structures. Several of the discs shade off laterally beyond the 'risers,' into more compact granular anisotropic bands. It would be impossible, we believe, to interpret this structure in terms of a cement line or cell boundary. The 'steps'
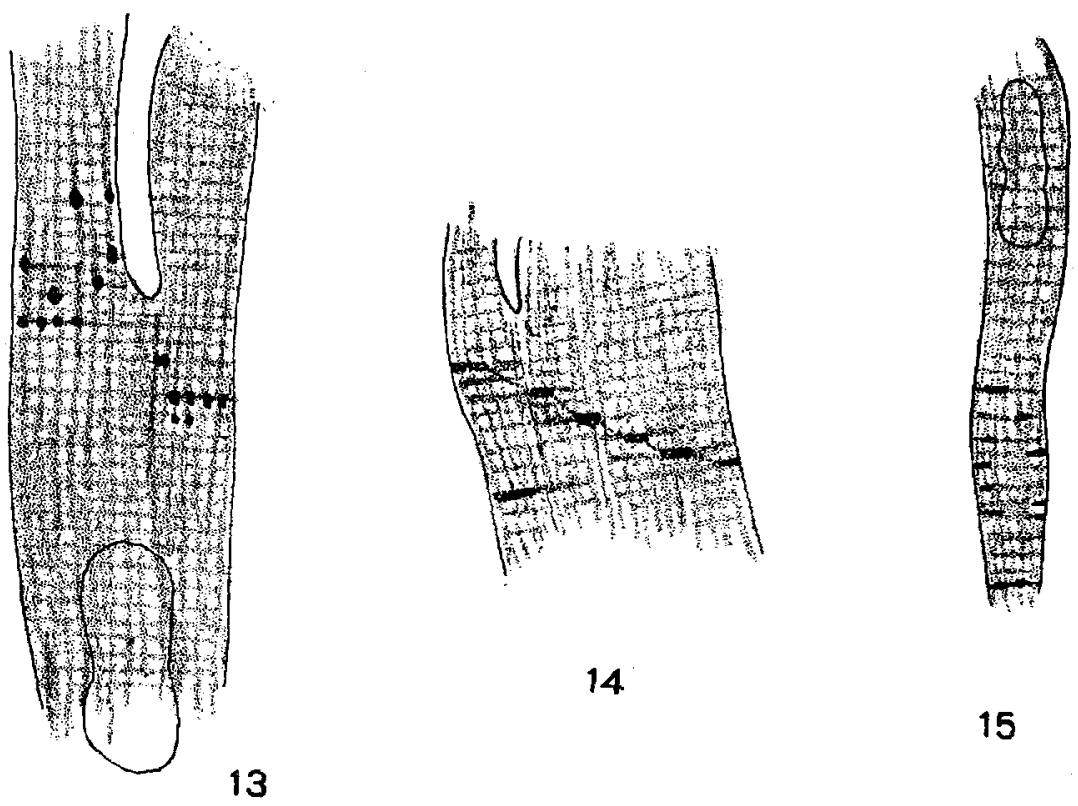

14

Fig. 13 Branching cardiae fiber of chipmunk, with numerous isolated Iarger and smaller oval discs, for the most part at the darker levels of the fibrillae.

Fig. 14 Cardiac fiber of chipmunk with step-like discs, composed of coarse granular thick 'steps' and delicate granular 'risers.'

Fig. 15 Fiber of humming-bird heart, showing the short, compact deeplystaining discs characteristic of this muscle.

of the disc here are clearly at the levels, and displace portions, of the darker bands, the entire structure lying superficially. 


\section{Opossum}

Conditions in the heart of the opossum are almost identical with those in guinea-pig. As concerns the intercalated discs, they differ only from their homologues in guinea-pig in being somewhat paler, more delicate and apparently less numerous. The deeper-staining character of the disc-containing portion of the muscle trabeculae is especially conspicuous in the opossum heart.

\section{Humming-bird}

Fig. 15, added chiefly for the purpose of completing the series of illustrations, shows a fiber of humming-bird heart muscle to illustrate the relative abundance, comparative form, and typical appearance of this tissue. Humming-bird heart muscle has been fully described in a former paper ${ }^{7}$ by one of the authors.

\section{Turtle}

In turtle heart the dises are fairly abundant (fig. 16). The dises here all appear as narrower or wider plates. They are again superficial and at the anisotropic levels, displacing the darker bands, and in many instances shading gradually into them at one or both ends. None of the rare varieties above described for mammalian muscle appear in turtle nor in lower forms, even step-like dises being very rare. The localization of the dises in definite transverse areas is apparently absent. The dises here are stouter than in frog and toad.

\section{Toad}

Fig. 17 illustrates conditions in the heart muscle of toad. The majority of discs are very narrow, though occasionally dises the width of an entire fiber appear. The dises are situated super-

${ }^{7}$ In this paper the darker band was regarded as the $Q$ band without consideration of the possibility that it may represent the $Z$ line modified in contraction. This possibility is discussed below. 
ficially and are of little depth, and apparently promiscuously placed. On close examination, under higher powers, the apparently compact delicate dises are seen to be granular. They are abundant only in cerfain areas, and not generally as plentiful as this particular illustration would indicate.
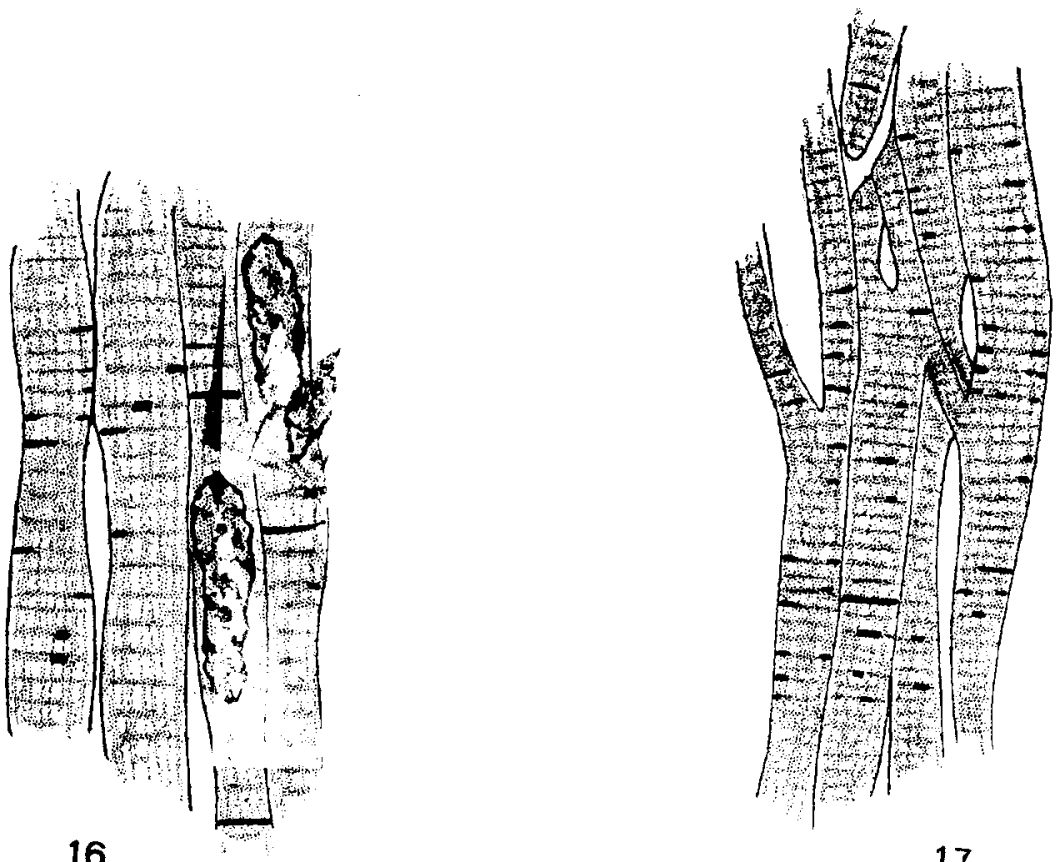

17

Fig. 16 Four adjacent fibers of turtle heart. The dises are superficial, numerous, and very like those of bird heart; always at anisotropic levels, usually compact and only very rarely in 'steps.

Fig. 17 Cardiac muscle of toid.

\section{a. Frog}

Practically the same description holk for frog (fig. 18) as for toad. The important point is the presence of dises in tissue below birds, where they have been deniel. There appears absolutely no evidence here that they mirk cell boundaries. 


\section{Trout}

In heart muscle of trout (fig. 19, representing several levels of focus), the discs are distinetly fewer in number than in higher groups. Occasionally also the oval type appears as thickenings
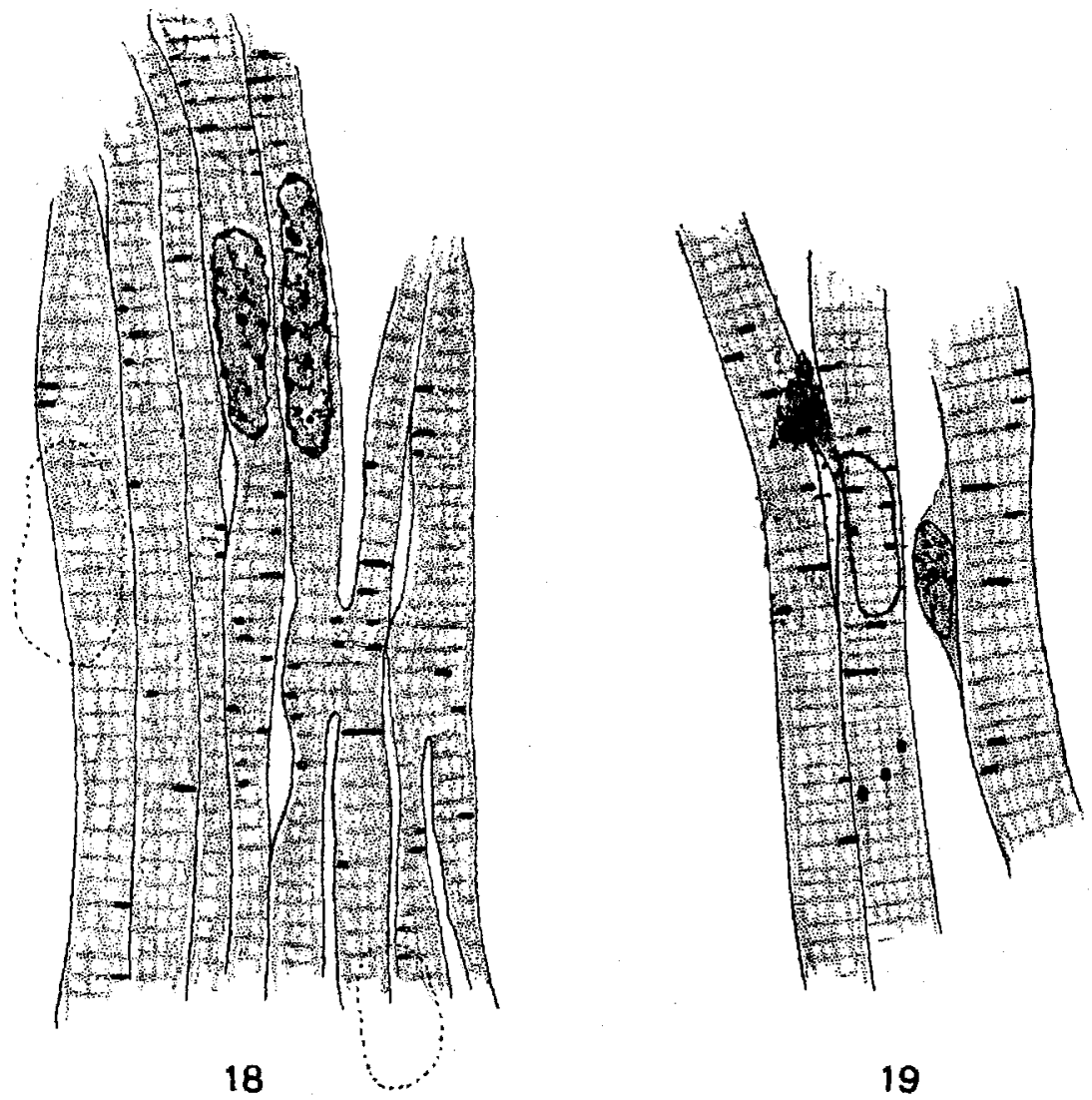

Fig. 18 Cardiac muscle of frog.

Fig. 19 Cardiac muscle of trout. The intercalated discs are similar to the simpler types of hearts of higher forms, but distinetly less numerous.

on the more distinct stouter (contracted) fibrils. The relation with respect to the nuclei and the anisotropic bands is the same as described for higher vertebretes. The discs are more abundant in contracted (dark r) regions, and near branches. Occasionally 
they extend across two fibers; and very frequently the discs are at the same level in adjacent fibers. They are always superficial, never appearing in the mid-line of a fiber when the nucleus is in focus. They appear in patches, and without regard to the position of the nuclei, and are only very rarely in 'steps.'

\section{B. YOUNG AND FOETAL MATERIAL}

\section{Guinea-pig}

a. Second, third and fourth weeks. In young guinea-pigs of the second to fourth week intercalated discs are already present (figs. 20 and 21). The majority, however, are in the shape of very narrow bands. These may be arranged in 'steps' connected by 'risers.' Many of the apparently compact dises are resolved under higher magnification into a series of blocks (local thickenings of fibrils), and the dises in general are less compact than at older stages. Again there is absolutely no evidence of cells and boundaries.

b. First week. During the first week dises are already present, and at the usual levels, but all have a light-staining character. In this tissue the granular dises shade gradually laterally into the darker bands.

c. Last week of gestation. During the last week of gestation, coincident with the appearance of striations, dises first make their appearance (fig. 23). No indication of dises could be seen at any earlier period. The dises here are narrow and consist of faintly-staining granules.

\section{Cat of four days}

In a cat embryo of four days the dises are already sparsely present. They are evidently just making their appearance. They are narrow, pale and granular.

\section{Child of four years}

In this tissue the dises are abundant, and mostly of the type of narrow plates of slight depth. Relative to their number in the 
adult heart, however, they are meager in amount. Whether this fact is due exclusively to the young, or, in part also, to the diseased condition (tubercular meningitis) is not at present clear. In the case of guinea-pig it is certain that the dises are relatively

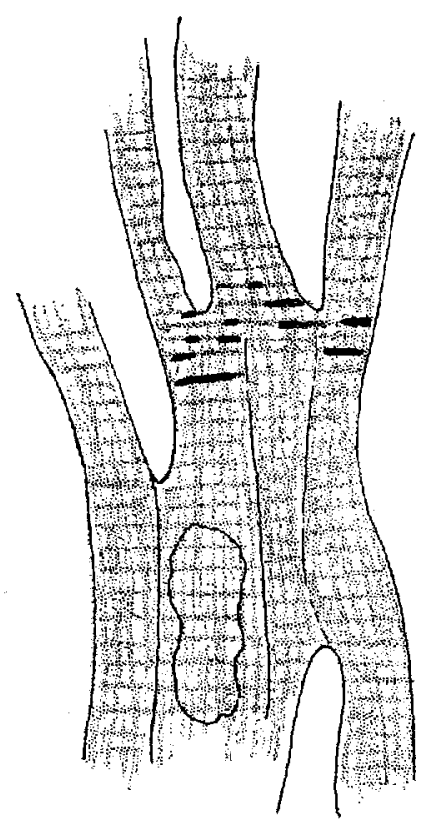

20

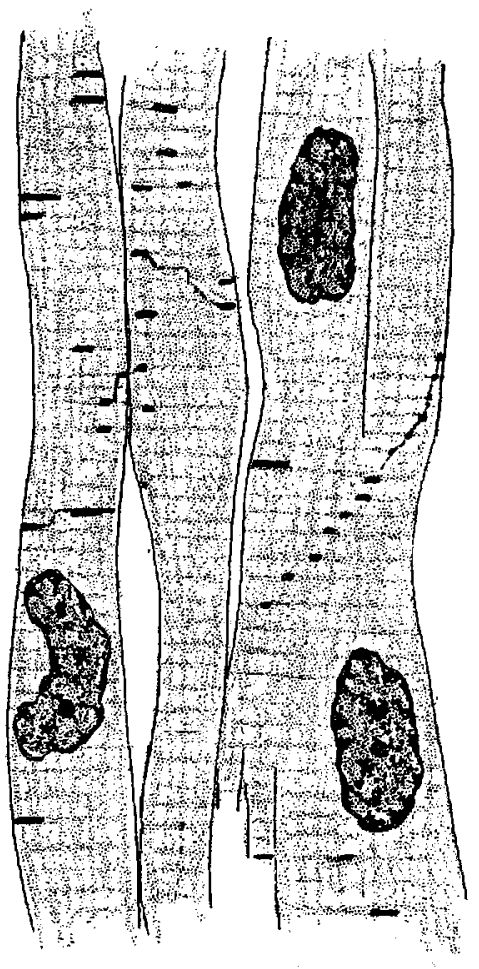

21

Fig. 20 Cardiac muscle of guinea-pig of four weeks of post-natal life. The intercalated discs appear aggregated in the axis of the mesh, are of simple character and mostly of paler or darker granular composition.

Fig. 21 From same preparation as fig. 20, showing the beginning of the formation of step-like discs.

less abundant and simpler in young than in the adults. Possibly the same relation obtains throughout mammals. However, there may also be a relationship between the discs and the condition of health and disease, a point which is now being investigated. 

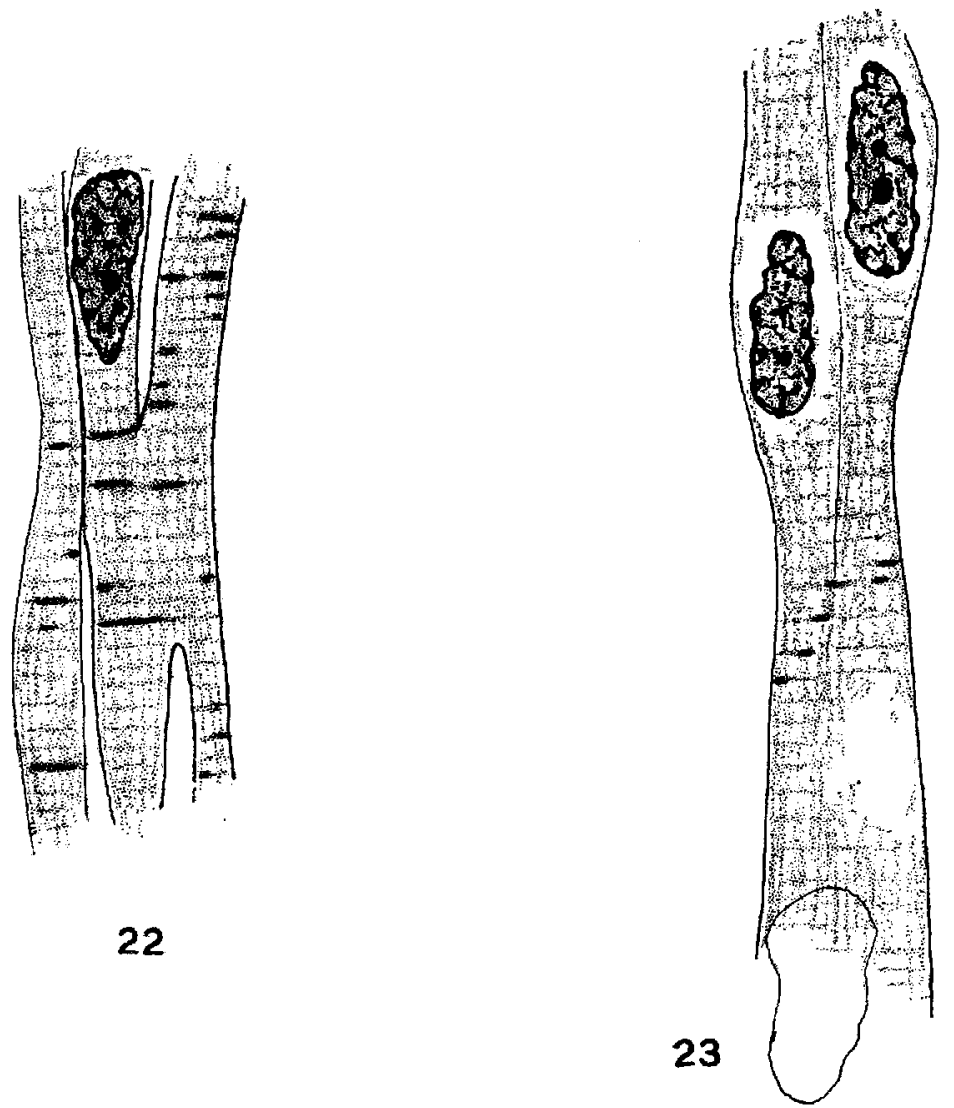

Fig. 22 Cardiac muscle of guinea-pig of first week of post-natal life. The dises are abundant, but exclusively of the granular (or less compact) narrow disc type.

Fig. 23 Cardiac musele of guinea-pig of last week of gestation. Cross striations and discs are just beginning to make their appearance.

\section{DISCUSSION}

An attempt to establish a relationship between rate of heartbeat and the number of dises was unsuccessful. If a series of animals, ranged according to the reported and observed relative abundance of intercalated discs, be compared with the same series ranged according to the rate of heart-beat, a correspondence appears at certain points between as many as three successive 
members (c.g., dog, man, sheep). But at other points there is absolutely no correspondence (e.g., sheep, cat, rabbit). The relationship, therefore, if it exists at all, cannot be a simple one. Factors, besides rate of beat, must affect the relative abundance of the dises. Such factors may be the force of the beat, or the instant or total amount of work done. That the rate, simply, does not determine the number of the discs appears furthermore from the fact that the dises are more abundant in the adult than in the young (e.g., guinea-pig and man), whereas the rate of heartbeat relative to age varies in the reverse ratio.

Moreover, the number of the dises varies in different portions of the same heart and in different individuals of the same species. This may mean, however, that they vary according to the phase or state of function, or perhaps according to the total amount of function (i.e., age of the individual). The observations regarding the relative abundance of the discs above stated may thus have no absolute (final) significance. Sufficient observations under uniform conditions have not yet been made for an accurate seriation of heart muscles from the standpoint of the abundance of dises. The physiologic significance (normal and abnormal) of these structures will appear in full only after a careful comparative study of the same individual under varying internal and external states, both normal and morbid; of animals of the same species at different ages; and of animals from the various groups under relatively uniform conditions of age, health and function. When all the factors helping to determine the presence and abundance of intercalated discs are thus known and accounted for, it may become possible to arrange animals in identical series from. the standpoint both of the rate of the heart-beat, and from the number of the intercalated dises. It seems clear that a relationship of some degree exists between the presence and abundance of these dises and function (rhythmic contraction), but in detail the relationship remains obscure.

In a histologic study of the lung of the white mouse one of us (Jordan) recently discovered that the tunica media of the proximal end of the pulmonary arteries consists of striped (cardiac) muscle for a considerable distance. This seemed to offer, there- 
fore, an excellent material for testing Heidenhain's interpretation of the intercalated dises as regions where new sarcomeres ('inokommata') are being added to the growing cardiac fibers. According to Heidenhain, the heart can enlarge only by interstitial growth, i.e., by terminal additions to the cardiac elements (trabeculae). In the case of the pulmonary arteries, however, there appears no reason for postulating growth by this method; the media here, developed from truncus arteriosus to be sure, can nevertheless, undoubtedly increase in amount in the same way as elsewhere in arteries. Moreover, striated muscle elsewhere does not increase by means, nor show evidence of, intercalated discs. But intercalated discs are present in the pulmonary media; furthermore the greater abundance of the dises here coincides with the time of less rapid growth, and less close developmental relationship with the heart. The presence of intercalated dises in the media of the cardiac end of the pulmonary arteries in the mouse would seem to be correlated with the 'beat' (strain?) here occurring in common with the heart. Still other facts controverting Heidenhain's interpretation that the intercalated discs provide for the 'interkalare Längenwachstum' of the cardiac fibers are: (1) the absence of transition stages between the discs and fully formed sarcomeres; (2) their absence during stages of most rapid (foetal) growth; (3) their numerical increase even after the heart has attained its normal bulk; (4) their presence in aged and diseased hearts; and (5) their considerable structural variation-every type capable of resolution, however, into very similar elementary units.

Militating most strongly against Zimmermann's interpretation of the discs in terms of intercellular elements, is our observation of the superficial location of the complex step-like forms. The more complex step-like types appear only where the entire fiber is included within the plane of section. Under such circumstances the successive 'steps' can be traced completely around a fiber by lowering and again raising the level of focus. Many such are then seen to form rings or even short spirals. The discs are of course not complete in the step forms, but are interrupted, con- 
sisting of 'steps' at different anisotropic levels connected by delicate membranes spanning the intervening 'isotropic' bands.

Attempts to alter the number of the dises experimentally by stimulation with varying strengths of an electric current have proved unsuecessful. Nor are they appreciably affected in tissue fixed in a state of rigor mortis. Material is now being collected for a study of these dises in various pathological conditions of the heart. Discs could not be demonstrated in Limulus heart.

A comparison of the illustrations accompanying the articles by Zimmermann's students, Werner and Palezewska, shows that in the human heart the dises are commonly bounded on both sides by the so-called ' $K$ rause's $Z$-lines,' whereas in lower mammals the dises are narrower than the space between two $Z$-lines, and consequently bounded on only one side by this line. Heidenhain likewise illustrates the discs in human heart muscle as bounded on both sides by a $Z$-line. Granting that this interpretation of the striped condition is correct, especially then in man do the discs correspond to the $Q$ or reputed anisotropic levels-as we have urged on the basis of a different interpretation-and in so far support our contention that they represent modifications of the fibrillae at anisotropic levels. But all of these illustrations differ from the far more widely prevalent condition of our material, in that the so-called ' $Z$-line' or 'Krause's membrane' is represented much too delicate. The darker stripe (seen both in fresh and stained material) is usually stout, and frequently almost half as wide as the alternate lighter segments; this is more particularly the case in human material. Since the sarcolemma is only occasionally, and then only imperfectly, festooned between these lines no definite suggestion is given of a 'Krause's membrane.' Especially in the regions where the discs appear abundantly are the dark stripes robust. Having naturally directed our attention chiefly to these regions, we interpreted appearances as indicating a condition of semi-contraction, according to the illustration of Tourneux (see Traité d'Histologie; par Prenant, Bouin et Maillard; tome 1, p. 442. Paris).

It seems possible, however, in the light of this illustration and the theoretical interpretation involved, that the fibers are in 
condition of full, or nearly full, contraction. During contraction the substances of the anisotropic and isotropic bands are supposed to intermingle and ultimately change their relative locations. Such a transition condition may account for the indistinct, or absence of, stratification of the anisotropic and isotropic substances under the micropolariscope. Moreover, in the contracted condition (according to 'Tourneux' diagram; see also M. Heidenhain, 'Plasma und Zelle,' '11, p. 677) the darker stripe is at the level of the $Z$-line, itself supposed to consist of anisotropic substance. The $Z$-line seems to have thickened by reason of the accumulation of 'anisotropic' substance about it, forming the 'contraction band' of Rollet. Thus the darker stripe may indeed represent the $Z$-line, plus considerable additional anisotropic substance. The 'Z-lines' of Heidenhain and Zimmermann correspond apparently to the darker lines in our specimens, representing more likely a 'contraction band.' The illustrations of these investigators are faulty in that they show the darker stripes too delicate, always single, continuous, and too uniform. If the darker stripes are indeed the $Z$-lines, now grown robust in contraction, the regions of the fibers containing the interealated dises are in a state of more pronounced contraction, according to the theory of Rollet and Tourneux. This deduction, then, is in complete accord with our position that the dises are somehow a concomitant of contraction; and further that they represent modifications (irreversible contractions?) of the fibrils at the dark (anisotropic) levels, the anisotropic substance having shifted in contraction to the $Z$-line. It seems clear that a complete elucidation of the question of the structure and function of the intercalated dises awaits fuller knowledge of the physical and chemical changes undergone by the cardiac myofibrillae during contraction. Our interpretation of the robust, sometimes double, dark stripes (the only stripes visible in non-human material) as the anisotropic bands seems in closer accord with our knowledge of skeletal and striped muscle generally. 


\section{SUMMARY AND CONCLUSIONS}

1. By the use of Zimmermann's technic it was possible to demonstrate intercalated dises in all heart muscle examined, except that of Limulus. Of lower vertebrates the material included that of turtle, lizard, frog, toad and trout, in which forms the presence of dises has been denied.

2. In guinea-pig, in which form only the matter was tested, intercalated discs appear early during the last week of gestation, coincidently with the appearance of striations. A progressive increase in number, complexity and density was noted during the first, second, third and fourth weeks of post-natal life. A similar more pronounced difference obtains between the heart of the young and that of the adult guinea-pig. In a cat embryo of four days the dises are already present but few in number, pale, and loosely granular in structure.

3. Compared with mammals (e.g., monkey, bat, chipmunk), in lower vertebrates the discs become progressively less numerous (except in birds, e.g., humming-bird), narrower, less compact (more granular) and less complex. Conditions with respect to the discs in young mammalian hearts are very similar to those in the hearts of lower vertebrates. With increase of age, there is a progressive increase in number, complexity, density and width of discs (e.g., guinea-pig).

4. The comparative study of vertebrate heart muscle gives no evidence favoring the interpretation of the dises as structures marking cell boundaries, e.g., cement lines or intercellular bridges.

5. Specific points in the evidence against an intercellular interpretation are: (a) their superficial location; (b) their relationship to the dark ('anisotropie') band, i.e., they displace these bands and shade laterally into them; (c) their position frequently over a nucleus; (d) their relation to the myofibrillae; (e) their random arrangement with respect to the nuclei; (f) structurally and tinctorially they seem to be of the same nature as the so-called anisotropic substance; and (g) their absence before the appearance of striations. 
6. The discs are interpreted in terms of local contractions (or aggregations of 'anisotropic' granules) in the muscle fibrils. The different modes of association of such single contraction foci give rise to all the various types of dises described, i.e., granules, blocks, ovals, plates (composed of closely apposed longer and shorter rodlets), 'combs,' 'steps' and saw-teeth forms.

7. The presence of dises would seem to be correlated with the function of rhythmic contraction characteristic of cardiac muscle, and may represent a fixed phase of a contraction wave (local or general), or more probably is the result (of the nature of an irreversible strain condition) of the total amount of function. The latter idea is supported by the fact of (a) their absence in the mammalian foetus, and their increasing abundance and coarseness with age; (b) their general location in lines corresponding roughly with the axes of the heart muscle mesh; (c) in general, their greater abundance in hearts of more rapid beat; and (d) their presence also in the striated muscle of the media in the proximal (beating) end of the pulmonary arteries (e.g., mouse).

\section{IITERATURE CITED}

Heidentain, M. 1901 Über die Struktur des menschlichen Herzmuskels. Anat. Anz., Bd. 20.

1911 Plasma und Zelle. Jena.

JordA.N, H. E. 1911 The structure of heart muscle of the humming bird, with special reference to the intercalated discs. Anat. Rec., vol. 5, no. 11.

MARCEAO, F. 1904 Recherches sur la structure et le developpement compare des fibres cardiaque. Ann. des Sc. Nat. Zool., vol. 19.

Palczewsea, Irene von 1910 Über die Struktur der menschlichen Horzmuskelfasern. Arch. f. mikr. Anat. u. Entwickl., Bd. 75.

Werner, Marie 1910 Besteht die Hérzmuskulatur der Säugetiere aus allseits scharf begrenzten Zellen oder nicht? Arch.f. mikr. Anat. u. Entwickl,, Bd. 75 .

ZimmermanN, K. W. 1910 Über den Bau der Herzmuskulatur. Arch.f. mikr. Anat. u. Entwick1., Bd. 75. 